\title{
Socio-Environmental Vulnerability Index: An Application to Rio de Janeiro-Brazil
}

\author{
Fernanda Siqueira Malta ${ }^{1 \dagger}$ and Eduarda Marques da Costa ${ }^{2 \dagger *}$ \\ ${ }^{1}$ Instituto Brasileiro de Geografia e Estatística, Rio de Janeiro, Brazil, ${ }^{2}$ Center of Geographical Studies, Institute of Geography and \\ Spatial Planning, Universidade de Lisboa, Lisbon, Portugal
}

Objectives: The concept of vulnerability has been used more frequently in several studies, in an attempt to better understand the specificities and needs of different population groups, both in environmental and socio-economical terms. The aim of this study is to identify, characterize and analyze populations in situations of socio-environmental vulnerability in the city of Rio de Janeiro, based on social, economic, environmental and public health indicators organized into a summary index - the Socio-Environmental Vulnerability Index.

Methods: The methodology integrated 15 indicators in a Multi-Criteria Decision Analysis into a Geographic Information System.

Results: According to our results, socio-environmental vulnerability in Rio de Janeiro is aggravated by at-risk situations and environmental degradation. These aspects are jeopardized by the population density in slum areas, where the most disadvantaged groups live in a process of environmental and urban exclusion.

Conclusion: The study concludes about the importance of these tools in guiding resource

OPEN ACCESS

Edited by:

Lyda Osorio,

University of Valle, Colombia

*Correspondence:

Eduarda Marques da Costa

Eduarda.costa@campus.ul.pt

${ }^{\dagger}$ These authors have contributed equally to this work and share first

authorship

Received: 16 July 2020 Accepted: 02 February 2021

Published: 29 March 2021

Citation:

Malta FS and Marques da Costa E

(2021) Socio-Environmental Vulnerability Index: An Application to

Rio de Janeiro-Brazil. Int J Public Health 66:584308. doi: 10.3389/ijph.2021.584308 allocation and their contribution to formulating and implementing more effective public policies.

Keywords: vulnerability, socio-environmental vulnerability index, geographic information systems, decision support systems, Rio de Janeiro

\section{INTRODUCTION}

In recent years, the term vulnerability has become a keyword in studies on environmental risks and climate change issues. At the same time - and this may be one of the reasons for its growing popularity - vulnerability is a rather diffuse term [1]. Various definitions of vulnerability have emerged and are used in different disciplinary contexts, whether related to sustainability [2], natural and environmental risks $[3,4]$ within the context of climate change $[5,6]$ or in social and economic fields [7-10]. Another approach to vulnerability that is growing relevance, can be seen in the context of health $[11,12]$. "The concept of vulnerability implies some risk combined with the level of social and economic liability, and the ability to cope with the resulting event. Thus people become "vulnerable" if access to resources either at a household, or at an individual level is the most critical factor in achieving a secure livelihood or recovering effectively from a disaster" ([13], pp. 370, 371).

In epistemological terms, Hufschmidt [14] classified vulnerability in two research areas: "the 'human ecologist school', also labelled the 'Chicago school' [15] or 'behavioral paradigm' [16, 17], 
and the 'structural paradigm' (or better 'view') associated with Sen's [18] 'entitlement' approach” (p.623).

The concept of vulnerability become more commum and broad, progressively adapted for each field of knowledge [19]. Another perspective [20], considered that in social and economical context, vulnerability follows three approachs: "economic strengthening, poverty and social exclusion"; "multiple pathways of vulnerability" (initially pointed by [21], p. 268); and the "resilience perspective".

For the first approach [22], authors conceptualize vulnerability in terms of either poverty dynamics, food security or sustainable livelihoods. However [23], quoting [24, 25], consider that vulnerability due to poverty, is not only dependent on current income inadequacy, but rather insecurity and exposure to the risk of future low income. Also other authors consider that poverty cannot be conflated with vulnerability, and that vulnerability analysis in the scope of poverty, requires forward-looking information including indicators of risk [20, 26-28].

In that context, the second perspective of Adger [21], points to a more integrative and systemic approach, assuming that vulnerability results from various causes and effects of vulnerability, integrating natural hazards, social vulnerability, and economic vulnerability.

In the last years, the third perspective emerges in the literature. The discussion of vulnerability linked to resilience process emerged due to evidence on the capacity of some communities to face with external pressures resulting from social, political and environmental change [29], showing the capacity for adaptative action [21]. This adaptative actions are supported by the development of new vulnerability tools and methods across resource management, social change, urbanization and climate change stress factors $[5,7,21,30-34]$.

The literature defends that level of vulnerability depends on the balance between risk and responses of the system. Ones [35] presents the notion of 'spatial vulnerability' as the "Access to a fair distribution of resources within social space shapes and is shaped by the nature and degree of vulnerability" (p. 230), while for Cutter et al [7] the concept of social vulnerabilty is related to: gender, race and ethnicity, age, family structure, employment, poverty, limited access to resources such as information, knowledge and technology, limited access to political power and representation (marginalization, exclusive), limited social capital including social networks and connections, vulnerable housing and low access to critical services such as communication, transportation, power supply, water supply, sanitation, education, medical services and other.

Another definition of social vulnerability considers four dimensions: socioeconomic status, household composition and disability, minority status and language and infrastrucutres and services [36,37] while other [38], discuss the perspective of social equity in the definition of urban resilience planning based on distributional, recognitional, and procedural equity dimensions.

These dimensions are represented by indicators that could be organized depending the objective of the analysis: contextoriented, outcome-oriented and participation/actor-oriented perspectives [39]. Measures of vulnerability can not be represented by a single indicator defending the need to create index or typologies supported in multiple indicators related to distinct dimensions of vulnerability and, in particular, social vulnerability.
The construction of the index is based on the production of indicators. These can be defined as a measure, most often quantitative, used to replace, quantify or operationalize a concept [40]. Indicators are considered, more and more, effective tools used to support planning and policy making activities, the resource allocation and the definition of priorities in the different spheres of government. Indicators enable, for example, the monitoring of the population's living conditions as well as the economic situation of a country $([41,42])$ and in that context a good indicator should be sensitive to the changing conditions of the environment and of society, be specific to the problem under analysis, be reproducible according to established methodological standards, provide a prompt response, be understood by the population, be robust to changes in methodology and be easily available or of low-cost [43].

The construction of indicators to assess living conditions and monitor public policies gained momentum in the 1990s with the United Nations introduction of the Human Development Index (HDI), devised by economist Mahbub ul Haq with the collaboration of economist Amartya Sen, winner of the 1998 Nobel Prize in Economics [44]. The HDI is a summarized measure of long-term progress in three basic dimensions of human development: income, education and health. This index has had major repercussions worldwide mainly because it is simple and easy to understand and represents the most holistic and comprehensive way of measuring development. Although the HDI broadens the perspective on human development, it does not cover or exhaust all aspects of development, including the issue of vulnerability. Therefore, new indices were developed to measure a diversity of themes not covered by the HDI.

The UNICEF's Multiple Indicator Cluster Survey (MICS) data is relevant to vulnerability as understood through the lens of "health, education, child protection and HIV/AIDS" [45]. Another useful source of secondary data is the World Bank's Living Standards Measurement Survey (LSMS), which includes survey data at community and household levels, including information on pricing and consumption to provide information on living standards [10]. The third example is the Social Vulnerability Index (SoVIVR) created at the University of South Carolina [7] and the identically named Social Vulnerability Index (SVI) developed at the U.S. Centers for disease Control [46].

In Brazil, in the 1990s and 2000s, several actions were taken to create indices that could portray the socio-economic reality of different population groups. These included the Social Exclusion/ Inclusion Index [47], the Family Development Index - IDF [48], the Youth Vulnerability Index - IVJ [49] and the Urban Quality of Life Index - IQVU [50].

From 2010 on, other indices were developed to substantiate the development of public policies specifically targeted at population groups considered to be more vulnerable. Some examples are the São Paulo Social Vulnerability Index of the Fundação Sistema Estadual de Análize de Dados de São Paulo [49], the Health Vulnerability Index of the Municipality of Belo Horizonte, the Social Vulnerability Index of the Institute of Applied Economics Research and the Municipal Vulnerability Index of the Oswaldo Cruz Foundation [6]. 


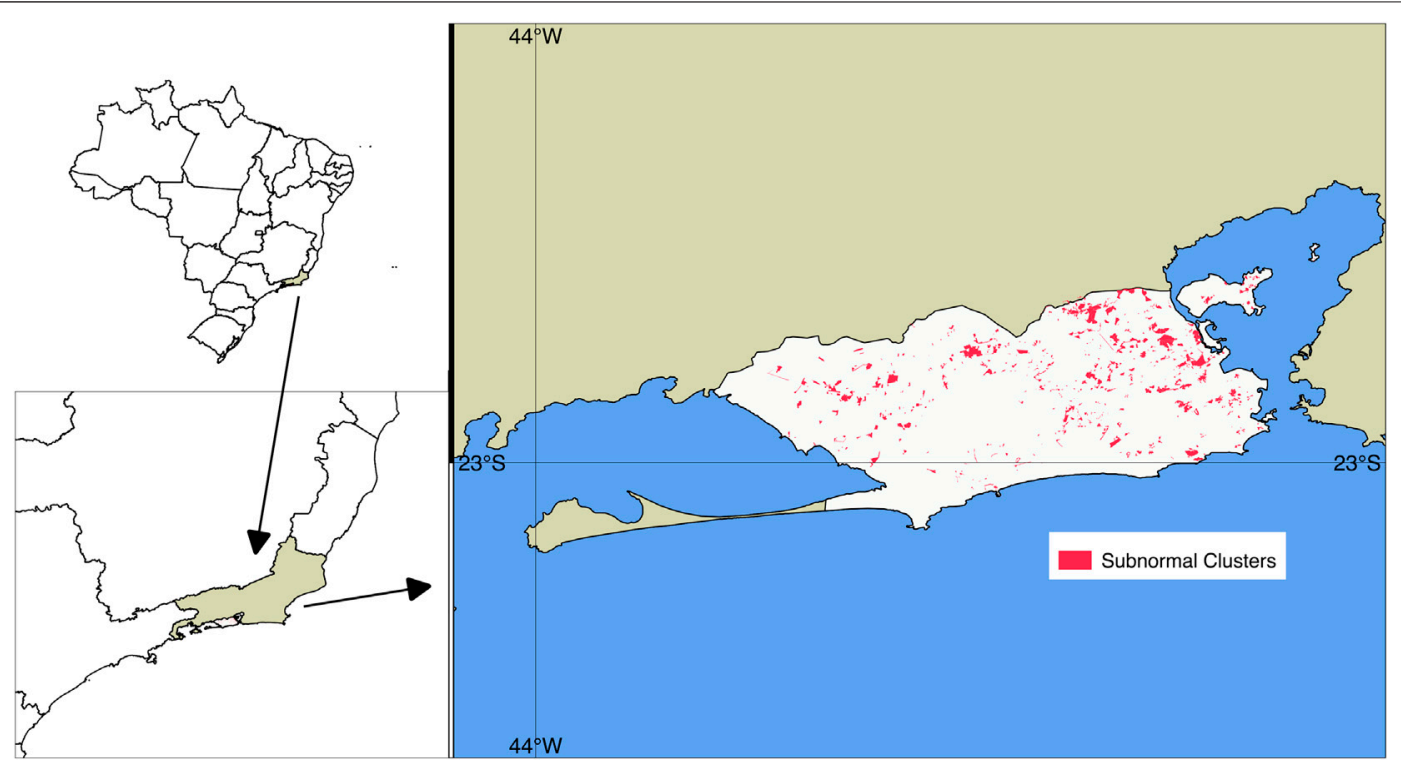

FIGURE 1 | Subnormal housing clusters in the municipality of Rio de Janeiro in 2010. Source: Instituto Brasileiro de Geografia e Estatística 2010.

Although the use of an accepted index as a benchmark to demonstrate the operationalization of social vulnerability, the index alone is insufficient to demonstrate model validity [51, 52]. For the authors, other methodologies could be reported to measure vulnerability, like cluster analysis involving diverse type of indicators, as presented for the Micro-regions and Meso-regions in Minas Gerais-Brazil [53].

The issue of vulnerability is complex and for each situation, vulnerable population and region needs specific information; for this reason, there are several indices, each one developed for a given reality, with different objectives and uses. In this context, this study proposes the creation of an index to analyze the "socioenvironmental vulnerability", integrating social, economic and urban infrastructure processes related to the precarious living conditions of the population (work, education, income, sanitation, mobility) with environmental, health and public safety conditions. The index is presented in a context-oriented perspective and their update could contribute to support the formulation and implementation of public policies, since for these actions it is essential to spatially locate the areas where the most vulnerable population are concentrated.

\section{The Studied Area: Rio de Janeiro}

In addition to having the highest concentration of population in the state, Rio de Janeiro is a metropolis that has long been known for its social inequality as well as problems regarding urban infrastructure, environmental risks and deficiencies in the health system and public safety [54-56]. This reality justifies the study of social and environmental vulnerability in the municipality, with the purpose of guiding the creation of public policies and the allocation of more appropriate public resources based on scientific evidence, resulting from a diagnosis made with information suited to the territory, scale and adequate time period.
Rio de Janeiro is the Brazilian city with the largest contingents of people living in subnormal housinf clusters, a technical name used by the Brazilian Institute of Geography and Statistics (Instituto Brasileiro de Geografia e Estatística - IBGE [57] to designate locations with informal housing built from fragile materials, invasions and a minimum of 51 households. Another key criterion for classifying such areas as subnormal housing clusters is the lack or inadequacy of basic public services such as water supply, sewage and rubbish collection services, in addition to generally being locations that are laid out in a dense and disorderly manner.

According to the 2010 Demographic Census, 23\% of the population of Rio de Janeiro live in subnormal housing clusters, commonly known as favelas. The proportion of people living in these locations varies significantly in the municipality, with great predominance in the central region, where although in absolute terms the population living in favelas is the smallest in the municipality, its proportion in relation to the total population is the largest, representing 35\% of the inhabitants of the region. Next is the northern region of the municipality with $27 \%$ of its population living in favelas, then Barra da Tijuca and Jacarepaguá region with $26 \%$, the southern zone with $17 \%$ and finally the western zone with $16 \%$. Figure 1 shows the spread of the 763 subnormal clusters in the city of Rio de Janeiro.

The existence of this number of subnormal housing agglomerates points to a serious problem related to an inconsistency between the municipality's housing policies and the demand for housing. Population growth in these regions between 2000 and 2010 was $27.7 \%$, while the regular city, with the exception of favela dwellers, grew at a rate that was eight times lower - only $3.4 \%$.

The presence of these favelas is a tragic indicator of economic dynamics and reveals the result of a lack of effective social policies 


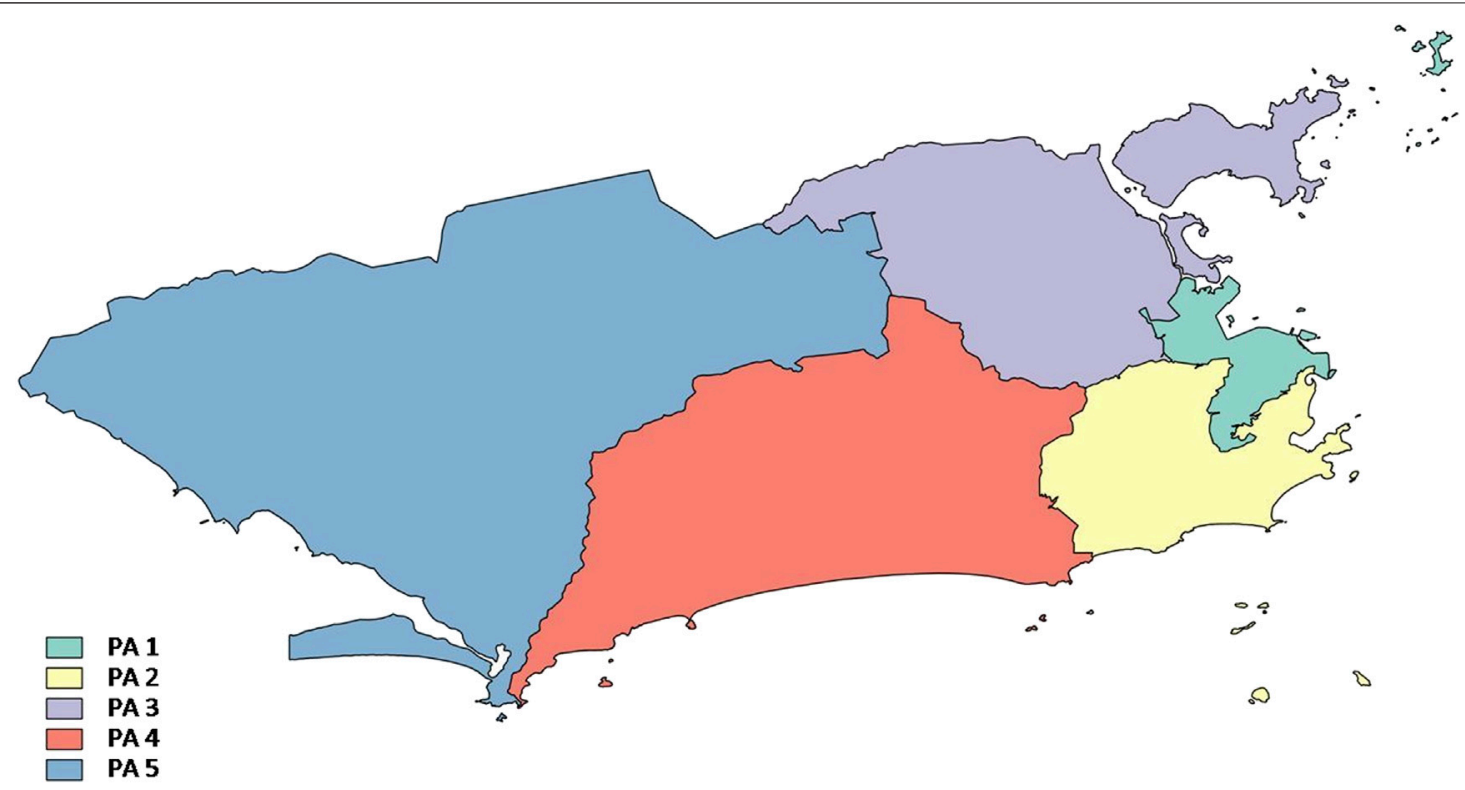

FIGURE 2 | Municipality of Rio de Janeiro by Planning Area. Source: Prepared by the authors from the city council of Rio de Janeiro, 2010.

over recent decades. In the city of Rio de Janeiro, hundreds of favelas, most of them on slopes or on river banks, create risky living conditions due to landslides and flooding [58] and the increasing climate change impacts in the territory $[59,60]$.

The amplitude of these urban problems and their impact on different territorial scales justify an interest in understanding and analyzing the issue of people living in situations of vulnerability in Brazil and particularly in the Rio de Janeiro municipality, where the problem of the favelas has become chronic.

The study area covers the entire municipality of Rio de Janeiro, the capital of the state of Rio de Janeiro, located in the southeastern region of Brazil. Rio de Janeiro has an area of $1,200 \mathrm{~km}^{2}$ where approximately 6.3 million people live, according to the 2010 Census, amounting to $40 \%$ of the state's total population. The Rio de Janeiro municipality is a fully urbanized region and is divided into Planning Areas (PAs), a division used by the city council to administratively serve the entire municipality.

Planning area 1 (PA 1) is the region of the historic center of the city, and also the area that has undergone the largest transformation in the urban scenario. Planning area 2 (PA 2), known as the South Zone, corresponds to the expansion area of the city promoted by the implementation of a tramway system in the second half of the 19th century, and is located between the Atlantic Ocean and the Tijuca Massif. Planning area 3 (PA 3), also known as the North Zone, concentrates the largest population contingent in the municipality (40\%) as it is the most densely populated. Planning area 4 (PA 4) has an extensive lowland area bounded by the Tijuca and Pedra Branca massifs and the Atlantic Ocean. This region encompasses the neighbourhoods of Barra da Tijuca and Jacarepaguá. Planning area 5 (PA 5), also known as the West Zone, has the second largest population of the municipality and the lowest population density. The low density is due to the fact that this is a region with a vast territory. This region includes the three most populous neighbourhoods of the city: Campo Grande, Bangu and Santa Cruz (Figure 2).

\section{METHODS}

The Socio-Environmental Vulnerability Index (SEVI) was built by integrating multi-criteria decision analysis (MCDA) methodology, more specifically the analytic hierarchy process (AHP), with a Geographic Information System (GIS) [61]. The proposed SEVI is made up of fifteen indicators based on bibliographic review and discussions with specialists in the fields of Sociology, Economics, Urban Infrastructure, and Environment, Health and Safety.

These indicators were grouped into three components: Socioeconomic, Urban Infrastructure, and Environment, Health and Safety. Each component is made up of the indicators below.

The indicators used in the construction of the SEVI seek to highlight different situations that indicate exclusion and vulnerability in the Brazilian territory, in a perspective that goes beyond identifying poverty perceived merely as insufficient monetary resources Table 1 . The components of the SEVI correspond to sets of assets, resources or structures whose access, absence or insufficiency indicate that the standard of living is low, suggesting, at the limit, non-access and nonobservance of social rights.

After selecting the above-mentioned indicators, the proposed methodology is divided into three stages. Data entry is one of the major stages and requires special care. The indicators used in the construction of the SEVI were standardized, becoming dimensionless and varying between 0 and 1 , where the 


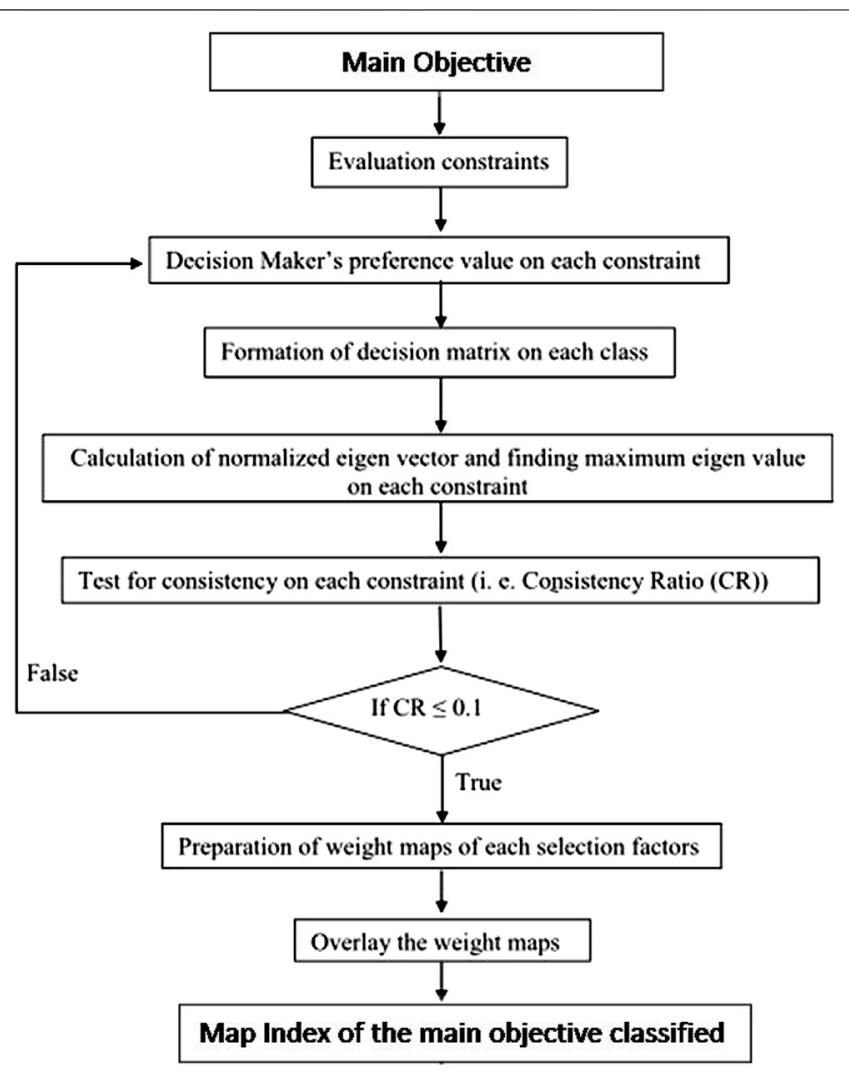

FIGURE 3 | Conceptual flowchart of the AHP. Source: Prepared by the authors.

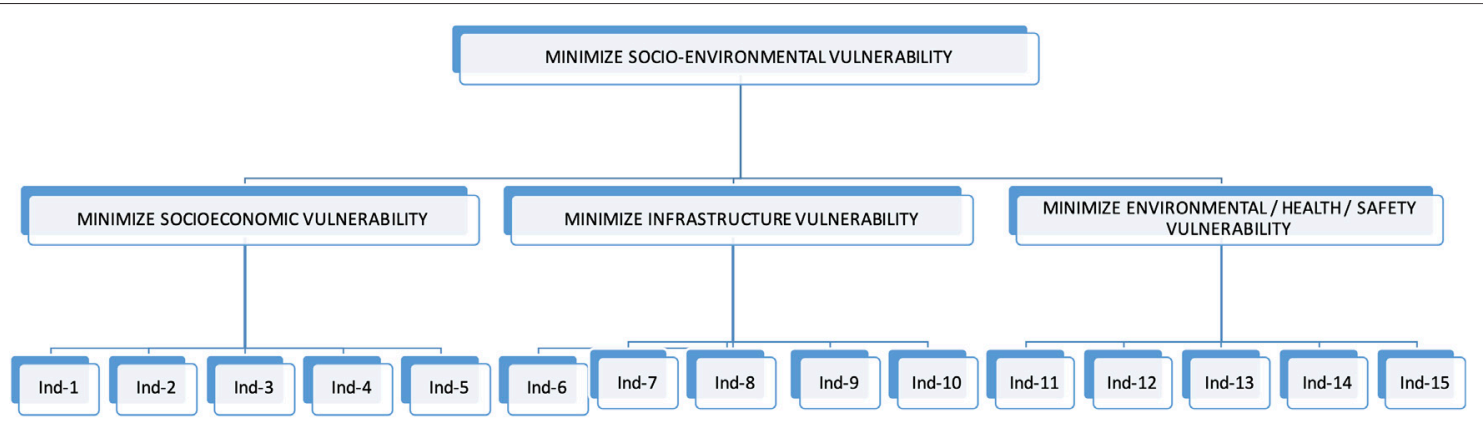

FIGURE 4 | Hierarchy of objectives of the multi-criteria analysis. Source: Prepared by the authors.

vulnerability is greater the closer it gets to 1 . It should be noted that zero does not represent the absence of vulnerability but the smallest relative value, and vice-versa for a value of 1 .

After this stage, the standardized indicators were transferred to a GIS and the multi-criteria analysis methodology for SEVI construction was applied to them.

Due to methodological choice and for analytical simplicity, the Analytic Hierarchy Process (AHP) method was used. It was created in the 1970's by Thomas L. Saaty [65] and is one of the main methods of the American school. This method is based on the hierarchical structure of a complex problem, suited to the analysis proposed by our study, which is related to socioenvironmental vulnerability. This structure consists in defining the global objective and decomposing the system into several levels of hierarchy, enabling us to see the system as a whole as well as its components. In addition, it is possible to analyze the interactions of the components of the decomposition and to ascertain the impacts that they exert on the system.

The AHP enables a structured decision-making approach using the judgment of specialists, and it includes five stages: 1) definition of the problem, 2) hierarchical construction and 
development of the problem into component factors related to the objectives of the problem, 3) construction of the comparison matrix, 4) calculation of the Eigen vector, main Eigen number, consistency index and consistency ratio, and 5) if there are inconsistencies in the decision process, revision of the comparison matrix until a consensus is reached. The conceptual flowchart of the AHP is shown in Figure 3.

Starting from the construction of the hierarchy, the criteria, i.e., the 15 indicators of the SEVI's three components Figure 4 were compared on a pair-to-pair basis according to their importance in achieving the main objective - minimizing Socio-environmental Vulnerability. This comparison was substantiated by the relative importance scale [65], based on the analysis of specialists in the fields of Sociology, Economics, Urban Planning, Environment, Health and Safety.

After normalizing the original comparison matrix, it was possible to calculate the weight of each indicator (Eigen vector) and the main Eigen number $\left(\lambda_{\max }\right)\left(\lambda_{\max }\right)$ which is obtained through the sum of the product of each element of the Eigen vector by the total of the respective column of the original comparison matrix).

Having obtained the $\left(\lambda_{\max }\right)\left(\lambda_{\max }\right)$, it was possible to calculate the value of the Consistency Index (CI) of the comparison matrix using the formula:

$$
\mathrm{CI}=\frac{\left(\lambda_{\max }-n\right)}{(n-1)}
$$

where $n$ is the matrix order, which in this case equals 15 .

Saaty [65] proposes the calculation of the Consistency Ratio (CR), obtained with the formula:

$$
\mathrm{CR}=\frac{\mathrm{CI}}{\mathrm{RCI}}
$$

where CI corresponds to the Consistency Index and RCI corresponds to the Random Consistency Index calculated for square matrices of order $\mathrm{n}$ by the Oak Ridge National Laboratory in the United States. If CR is greater than 0.1, the comparison matrix is inconsistent and should be revised. Since $\mathrm{CR}<0.1$ the comparison matrix is consistent. For $n=15, \mathrm{RIC}=1.59$ and we obtain the value of $\mathrm{CR}=0.0997$.

After this stage it is possible to construct the normalized maps for each indicator-criterion, apply the AHP to the criteria maps and finally obtain the index map of the main classified objective.

Statistical processing of the data was carried out by means of SAS software and the mapping, spatial analyses and AHP by means of the QGIS open source program.

\section{RESULTS}

As mentioned above, the SEVI ranges between 0 and 1 , and the closer to one it is, the greater the socio-environmental vulnerability; conversely, the closer to 0 it goes, the lower the vulnerability. For better applicability, this index was divided into five equal bands:

\begin{tabular}{ll}
$\mathbf{0 . 0 0 0}-\mathbf{0 . 2 0 0}$ & Very low \\
\hline $0.201-0.300$ & Low \\
$0.301-0.400$ & Medium \\
$0.401-0.500$ & High \\
$0.501-1.000$ & Very high \\
\hline
\end{tabular}

The results were presented by $\mathrm{PA}$, in accordance with the territorial macroplanning approach existing in the city council of Rio de Janeiro.

Approximately half of PA 1's area is classified as having medium socio-environmental vulnerability $(48.3 \%), 27.4 \%$ as having low socio-environmental vulnerability, $23.6 \%$ as having high socio-environmental vulnerability and $0.7 \%$ as having very high socio-environmental vulnerability. The highest point of the region's very high vulnerability lies in the Morro da Providência favela, which has more than half the indicators that make up the SEVI which are classified as high or very high vulnerability. There are no cases of very low socio-environmental vulnerability in this planning area. The population of this region has been the object of several studies about its high social vulnerability ([66]).

PA 2 shows very different behavior from PA 1. 71.2\% of the region is classified as having low socio-environmental vulnerability, $21.0 \%$ as having medium vulnerability and $7.8 \%$ as having high vulnerability. There are no cases of very low or very high socio-environmental vulnerability. The high point of the high-vulnerability region is the Rocinha favela with a population of 69,161 , according to the 2010 Census, making it the largest favela in Brazil.

Rocinha has high or very high indicators of the socioeconomic component, low indicators of urban infrastructure, very high susceptibility to slippage and high infant mortality. Although there have been investments in infrastructure, such as water supply, sewage and rubbish collection, other socioeconomic problems concerning health and environmental risk are still very much present in this region.

Over half of the PA 3 region is characterized as having medium socio-environmental vulnerability (59.8\%), 20.7\% as having low vulnerability, $18.0 \%$ as having high and $1.5 \%$ very high socio-environmental vulnerability. In the region classified as having very high vulnerability, the Fazenda Botafogo and Bairro da Pedreira favelas are prominent. In these two regions all the socio-economic indicators, in addition to the infant mortality indicator, are classified as very high.

PA 4 is divided between low (43.3\%) and medium (43.5\%) socio-environmental vulnerability. The high-vulnerability areas occupy $13.2 \%$ of this region. The high point of the areas of high vulnerability lies in the Rio das Pedras favela, the third largest in Brazil, which according to the 2010 Census has 54,793 inhabitants. This region has practically all the indicators of the socio-economic component classified as high or very high vulnerability, very high risks of inundation and flooding, as well as very high violent lethality.

The PA 5 region is divided into areas of average (42.6\%) and high $(48.5 \%)$ socio-environmental vulnerability. Only $2.0 \%$ of this region is classified as having low vulnerability. PA 5 has the highest percentage of very high socio-environmental 
vulnerability in relation to other planning areas (6.9\%), concentrated mainly in the neighbourhoods of Guaratiba, Paciência and Santa Cruz, which are not necessarily favela areas.

When we analyze the final results of the SEVI for the entire municipality of Rio de Janeiro, it can be seen that the majority of the region is classified as having medium socio- environmental vulnerability (44.0\%). Then $30.5 \%$ of the territory is classified as a having high socio-environmental vulnerability, a situation that is more prominent in PA 5.21.9\% of the territory was classified as having low socioenvironmental vulnerability, a situation prevailing in PAs 1 , 2 and 4 . 3.6\% was classified as having very high socio-

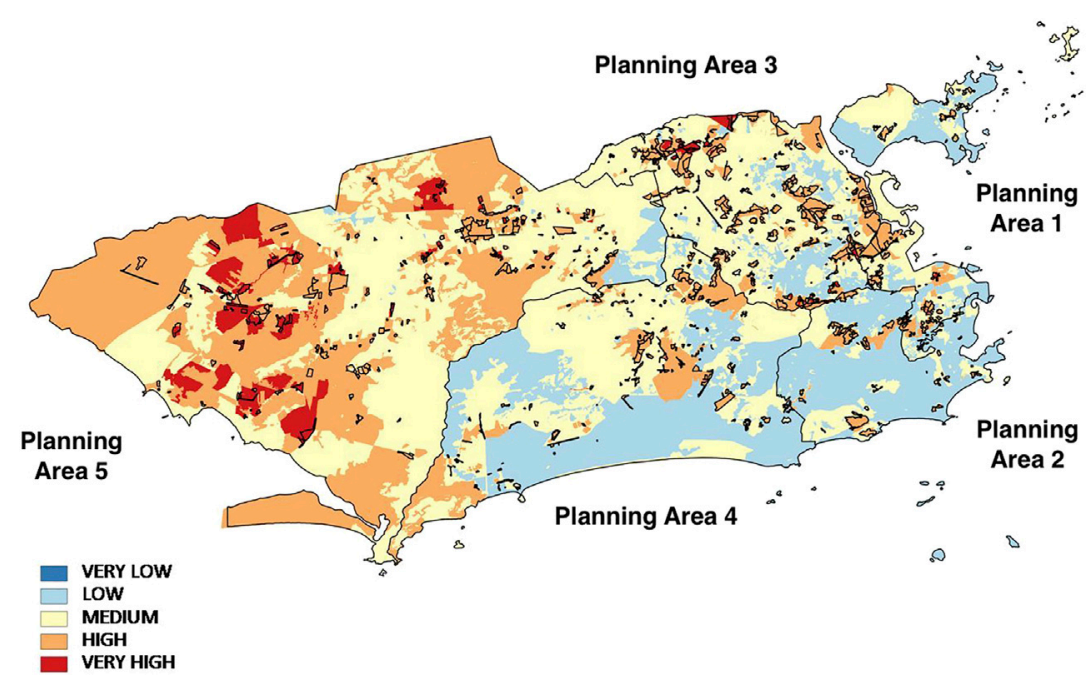

FIGURE 5 | Map of the Social and Environmental Vulnerability Index and Subnormal Clusters in 2010. Source: Prepared by the authors.

TABLE 1 | List of Indicators that support the Social-Environmental Vulnerability Index (SEVI).

Components

Socio-economic Component

Urban Infrastructure Component

Environment, Health and Safety Component

Indicators

Indicator 1: Percentage of mothers who are head of the household, who did not complete basic education and who have at least one child under the age of 15

Indicator 2: Percentage of children living in households where none of the residents completed basic education

Indicator 3: Percentage of people aged 15 to 24 who do not study, do not work and whose per capita household income is equal to or less than half the minimum wage

Indicator 4: Proportion of people whose per capita household income is equal to or less than half the minimum wage

Indicator 5: Percentage of people aged 18 or over who did not complete basic education and are in an informal occupation

Indicator 6: Percentage of people living in households with a per capita income of less than half the minimum wage and commuting over $1 \mathrm{~h}$ to get to work

Indicator 7: Ratio of residents per household

Indicator 8: Percentage of households without a storm drain/manhole - openings that give access to underground enclosures through which rainwater drains

Indicator 9: Percentage of people in households with inadequate water supply and sewage

Indicator 10: Percentage of people in households with no rubbish collection service

Indicator 11: Susceptibility to slippage

Indicator 12: Risk of inundation and flooding (source: Index of susceptibility of the environment to flooding - 2010)

Indicator 13: Mortality up to one year of age

Indicator 14: Percentage of households without trees in their yard

Indicator 15: Violent lethality
Sources

Census, 2010 [57]

Census, 2010 [57]

Census, 2010 [57]

Census, 2010 [57]

Census, 2010 [57]

Census, 2010 [57]

Census, 2010 [57]

Census, 2010 [57]

Census, 2010 [57]

Census, 2010 [57]

Fundação geo-rio 2013 [62]

Miranda 2016 [63]

Census, 2010 [57]

Census, 2010 [57]

Instituto de segurança pública -

Rio de Janeiro 2013 ([64])

Source: Selected by the authors. 
environmental vulnerability, with a higher concentration in PA 5. There were no cases of very low socio-environmental vulnerability (Figure 5).

\section{DISCUSSION}

According to Malczewski and Ogryczak [67], since the 1990s the use of the multi-criteria analysis methodology has been growing in territorial and urban planning. Currently, multi-criteria analysis is increasingly integrated into GISs, creating a robust tool to aid spatial analysis processes through modelling and to support decision-making in issues with spatial distribution and consequences. Efforts to integrate GIS and multi-criteria analysis in the late 1980s and early 1990s may be associated with increasing GIS development [61]. Sharifi et al. [68] also claim that the integration of GIS and multi-criteria analysis provides an important methodology in the creation of options to reduce environmental and socio-economic impacts, as well as to assess and solve these impacts in the territory.

The integration methodology between GIS and multi-criteria analysis used in the SEVI calculation corroborates other studies [69], where the author states that the integration between multicriteria decision-making techniques and SIGs represents a considerable advance in spatial analysis involving urban planning, compared to the conventional map overlay approaches.

The importance of this methodology can be seen from the growing number of publications in the most diverse areas and regions of the world. Examples include the studies: where this methodology is used in land use planning in Switzerland [70]; when identifying sites for the construction of sanitary landfills in the Lake Beys region of Turkey [71]; in the construction of a flood risk map in Terengganu, Malaysia [72]; in locating potential sites for ecotourism in Kenya [73]; when identifying suitable regions for urban development in Ulaanbaatar, Mongolia [74]; in Brazil, in the analysis on the social fragility of the urbanized area of the Viçosa - MG municipality [75]; to determine the Sustainability Index of the Sugar-Ethanol Sector [76]; and in the analysis of the quality of urban life of the population in the city of Rio de Janeiro [77].

In this way, the multi-criteria analysis methodology integrated in GIS is being consolidated as an extremely useful resource in public and private management. For this purpose, it is necessary to understand the tool as a resource for reflecting on practices and an aid to decision-making, ensuring transparency and the possibility of incorporating subjective value judgments in the process [78]. In the specific case of this article, the integration of the methodologies aims to assist the processes of urban planning and land management.

Socio-environmental vulnerability is directly related to the urbanization of Brazil, where in 2010 over $80 \%$ of the Brazilian population lived in urban areas. In addition to concentrated urbanization, this change occurred in only a few decades, so the infrastructure of these cities did not keep pace with such growth. This rapid and disorderly process of urbanization resulted in a number of consequences, most of them negative. The lack of urban planning and of a less concentration-oriented economic policy contributed to the occurrence of some problems that persist to this day. One of the main problems arising from accelerated urbanization in Brazil was the concentration of wealth and consequently an increase in inequality [79].

This unequal formation of the social structure is expressed in the urban structure, i.e., the right to the city is not just and equal for all its inhabitants. Therefore, the most vulnerable groups suffer from socio-spatial segregation. In the case of the municipality of Rio de Janeiro this segregation occurs in favela regions, confirming Rodrigues [80] observations regarding the struggle for the right to the city.

From the results found in this article, it can be seen that the highest SEVI values are found in favela regions, thus confirming that the poorest populations suffer most of the negative effects of urbanization, confirming initial studies [7] where the authors discuss the variations of vulnerability in time and space among different social groups. The struggle for the right to the city and for the right to housing, one of its central components, emerged as a counterpoint to a model of exclusionary urbanization that over decades of accelerated urbanization absorbed large contingents of the poorest people in a few large cities, without ever effectively integrating them into the cities ([81-83]). In addition to the socio-economic problems, one of the dimensions of the struggle for the right to the city is the right to a healthy environment $[84,85]$, which requires access to sanitation, housing, security, infrastructure and health policies. The methodology and the results obtained for the SEVI can support these policies, contributing to the minimization of sociospatial segregation and consequently to a change in the current model of urbanization so that all residents have the same right to the city.

\section{Conclusion}

The methodology of integration between multi-criteria analysis and GIS developed in the construction of the SEVI represents an important tool for defining and validating policies for groups in situations of vulnerability. The creation of an index-map for the SEVI makes it easier to see the important aspects of the vulnerability processes, enabling the disaggregation of its components into maps, as well as maps of the indicators used in its construction. In this way it is possible to identify priority areas lacking specific policies and also to foster their monitoring.

The use of socio-economic, urban infrastructure, environmental, health and safety components in the construction of the SEVI is a combination that fully represents socio-environmental vulnerability and, in the specific case of this study, the reality of the most vulnerable groups in the municipality of Rio de Janeiro. These results should be taken into consideration by public authorities and other bodies dealing with this problematic context, so as to reduce situations of vulnerability and democratize the right to the city.

In order to apply it in other regions, we suggest the inclusion and/or substitution of indicators according to the reality of the region to be analyzed. In this way, through spatial knowledge of the most vulnerable areas it is possible to subsidize the creation of preparedness and response plans to deal with these problems and consequently to mitigate them. 


\section{DATA AVAILABILITY STATEMENT}

The datasets presented in this study can be found in online repositories. The names of the repository/repositories and accession number can be found below: <b>http://www.ppe. ufrj.br/index.php/pt/publicacoes/teses-e-dissertacoes/2018/183vulnerabilidade-socioambiental-proposta-metodologica-ediagnostico-para-o-municipio-do-rio-de-janeiro $</ b>$.

\section{AUTHOR CONTRIBUTIONS}

FM was responsible for the theoretical support, indicators selection, methodology, results and discussion. EC was co-responsible for the selection of references and written theoretical component, selection of indicators and discussion of results and conclusions

\section{REFERENCES}

1. Kuhlicke C, Scolobig A, Tapsell S, Steinführer A, and De Marchi B. Contextualizing social vulnerability: findings from case studies across Europe. Nat Hazards (2011). 58(2):789-810. doi:10.1007/s11069-011-9751-6

2. Turner BL, Kasperson RE, Matson PA, McCarthy JJ, Corell RW, Christensen L, et al. A framework for vulnerability analysis in sustainability science. Pnas (2003). 100(14):8074-9. doi:10.1073/pnas.1231335100

3. Marandola E, Jr, and Hogan DJ. Vulnerabilidades e riscos: entre Geografia e Demografia. Rev Bras Estud Popul (2005). 22(1):29-53.

4. Ministério do Meio Ambiente. Vulnerabilidade ambiental. Brasil: Ministério do Meio Ambiente (2007).

5. Füssel HM, and Klein RJT. Climate change vulnerability assessments: an evolution of conceptual thinking. Clim Change (2006). 75(3):301-29. doi:10. 1007/s10584-006-0329-3

6. Cruz FO. Mapa da Vulnerabilidade da População dos Municípios do Estado do Rio de Janeiro Frente às Mudanças Climáticas. Rio de Janeiro, Brazil: Fundação Oswaldo Cruz (2014).

7. Cutter SL, Boruff BJ, and Shirley WL. Social vulnerability to environmental hazards. Soc Sci Q (2003). 84(2):242-261. doi:10.1111/1540-6237.8402002

8. Fossati D. Economic vulnerability and economic voting in 14 OECD countries. Eur J Polit Res (2014). 53(1):116-135. doi:10.1111/1475-6765.12019

9. Instituto de Pesquisa Econômica Aplicada. Atlas da Vulnerabilidade Social nos municípios brasileiros. Brasília, Brazil: Instituto de Pesquisa Econômica Aplicada (2015). 77 p.

10. Parreira L, Marques da Costa E, and Ribeiro Filho V. Uma análise da vulnerabilidade social das Microregiões Geográficas do Estado de Minas Gerais, Brasil. Revista Geo UERJ (2017). 30-1:58-75. doi:10.12957/geouerj. 2017.2932127251

11. Silva MAI, Mello FCMD, Mello DFD, Ferriani MDGC, Sampaio JMC, and Oliveira WAD. Vulnerabilidade na saúde do adolescente: questões contemporâneas. Ciênc Saúde Coletiva (2014). 19(2):619-627. doi:10.1590/ 1413-81232014192.22312012

12. Eisenman DP, Wilhalme H, Tseng CH, Chester M, English P, Pincetl S, et al. Heat Death Associations with the built environment, social vulnerability and their interactions with rising temperature. Health Place (2016). 41(1):89-99. doi:10.1016/j.healthplace.2016.08.007

13. Proag V. The concept of vulnerability and resilience. Proced Econ Finance (2014). 18:369-376. doi:10.1016/S2212-5671(14)00952-6

14. Hufschmidt G. A comparative analysis of several vulnerability concepts. Nat Hazards (2011). 58:621-643. doi:10.1007/s11069-011-9823-7

15. Tobin GA, and Montz BE. Natural hazards: explanation and integration. New York, NY: Guilford Press (1997). 45 p.

16. Pelling M. Paradigms of risk In: M Pelling, editor Natural disasters and development in a globalizing world. London, United Kingdom: Routledge (2003). p. 3-16.

\section{FUNDING}

This work was developed with the support of the National Council for Scientific and Technological Development, through a grant from the Science Without Borders Program to carry out the Short Doctorate at the Institute of Geography and Spatial Planning at the University of Lisbon. In addition to funding from the Brazilian Institute of Geography and Statistics in the form of a leave of absence for full-time doctorate.

\section{CONFLICT OF INTEREST}

The authors declare that the research was conducted in the absence of any commercial or financial relationships that could be construed as a potential conflict of interest.

17. Smith K. Environmental hazards: assessing risk and reducing disaster. London, United Kingdom: Routledge (2004). 554 p.

18. Sen A. Poverty and famines: an essay on entitlements and deprivation. Oxford, United Kingdom: Clarendon Press (1981). 257 p.

19. Gallopín GC. Linkages between vulnerability, resilience, and adaptive capacity. Glob Environ Change (2006). 16(3):293-303. doi:10.1016/j.gloenvcha.2006. 02.004

20. Moret W. Vulnerability assessment methodologies: a review of the literature. Washington, D.C., United States: United States Agency for International Development (2014). 90 p.

21. Adger WN. Vulnerability. Glob Environ Change (2006). 16(3):268-281. doi:10. 1016/j.gloenvcha.2006.02.006

22. Alwang J, Siegel PB, and Jørgensen SL. Vulnerability: a view from different disciplines. Social Protection Discussion Paper Series (2001). Available from: http://siteresources.worldbank.org/SOCIALPROTECTION/Resources/SPDiscussion-papers/Social-Risk-Management-DP/0115.pdf/ (Accessed April 30, 2018).

23. Morrone A, Scrivens K, Smith C, and Balestra C. Measuring vulnerability and resilience in OECD coutries (2011). Available from: http://www.iariw.org/ papers/2011/morronepaper.pdf/ (Accessed April 30, 2018).

24. Paugman S. Poverty and social disqualification: a comparative analysis of cumulative social disadvantage in europe. J Eur Soc Pol (1996). 6(4):287-303. doi:10.1177/095892879600600402

25. de Haan A. Social exclusion: an alternative concept for the study of deprivation?. IDS Bull (1998). 29(1):10-19. doi:10.1111/j.1759-5436.1998. mp29001002.x

26. Naudé W, Santos-Paulino AU, and McGillivray M. Measuring vulnerability: an overview and introduction. Oxford Develop Stud (2009). 37(3):183-191. doi:10.1080/13600810903085792

27. O'Brien K, Quinlan T, and Ziervogel G. Vulnerability interventions in the context of multiple stressors: lessons from the Southern Africa Vulnerability Initiative (SAVI). Environ Sci Pol (2009). 12(1):23-32. doi:10.1016/j.envsci.2008.10.008

28. Prowse $M$. Towards a clearer understanding of 'vulnerability' in relation to chronic poverty. CPRC working paper. Chronic Poverty Research Centre (2003). 41 p.

29. Adger WN. Social and ecological resilience: are they related? Prog Hum Geogr (2000). 24(3):347-364. doi:10.1191/030913200701540465

30. Pelling M. The vulnerability of cities: natural disasters and social resilience. London, United Kingdom: Routledge (2003).

31. G Bankoff, G Frerk, and D Hilhorst eds. Mapping vulnerability: disasters. London, United Kingdom: Development \& PeopleEarthscan (2004). p. 236.

32. Ionescu C, Klein RJT, Hinkel J, Kavi Kumar KS, and Klein R. Towards a formal framework of vulnerability to climate change. Osnabrück, Germany: University of Osnabrück (2005). 16.

33. Bereciartua PJ. Vulnerability to global environmental changes in Argentina: opportunities for upgrading regional water resources management strategies. Water Sci Technol (2005). 51:97-103. doi:10.2166/wst.2005.0118 
34. Eakin H, and Luers AL. Assessing the vulnerability of social-environmental systems. Ann Rev Environ Resour (2006). 31:365-394. doi:10.1146/annurev. energy.30.050504.144352

35. Saatcioglu B, and Corus C. Exploring spatial vulnerability: inequality and agency formulations in social space. J Marketing Manag (2016). 32(3-4): 230-251. doi:10.1080/0267257X.2015.1103775

36. Centers for Disease Control and Prevention. Planning for an emergency: strategies for identifying and engaging at-risk groups. A guidance document for emergency managers. Atlanta, GA: CDC (2015).

37. BRACE. Social vulnerability index. Chicago: University of Illinois at Chicago, School of Public Health (2017). Available from: https://braceillinois.uic.edu/ climate-change-health/people-places-atrisk/svi/ (Accessed August 18, 2017).

38. Meerow S, Pajouhesh P, and Miller TR. Social equity in urban resilience planning. Local Environ (2019). 24(9):793-808. doi:10.1080/13549839.2019. 1645103

39. Murphy DJ, Wyborn Carina, Yung Laurie, and Williams DR. Key concepts and methods in social vulnerability and adaptive capacity. Gen. Tech. Rep. RMRSGTR-328. Fort Collins, CO: U.S. Department of Agriculture, Forest Service, Rocky Mountain Research Station (2015). p. 24.

40. Jannuzzi PM. Indicadores sociais no Brasil: conceitos, fonte de dados e aplicações. Campinas, Brazil: Alínea (2012).

41. Carley M. Indicadores sociais: teoria e prática. Rio de Janeiro, Brazil: Zahar (1985).

42. United Nations. Handbook on social indicators. Nova York, United States: United Nations (1989).

43. Barcellos C, and Minayo MC. Constituição de um sistema de indicadores socioambientais. Saúde e Ambiente Sustentável: estreitando Nós. Org. Rio de Janeiro, Brazil: Fundação Oswaldo Cruz (2002). p. 313-329.

44. United Nations. Human development report. Nova York, United States: Oxford University Press (1990).

45. UNICEF. Multiple indicator cluster survey (MICS) (2012). Available from: http://www.unicef.org/statistics/index_24302.html/ (Accessed April 30, 2018).

46. Flanagan BE. A social vulnerability index for disaster management. J Homeland Security Emerg Manag (2011). 8(1):1-22. doi:10.2202/15477355.1792

47. Sposati A. Mapa da Exclusão/Inclusão Social da cidade de São Paulo. São Paulo, Brazil: Educ. (1996).

48. Barros R.P., Carvalho M., and Franco S. O indice de desenvolvimento da família (IDF). Brasília, Brazil: Instituto de Pesquisa Econômica Aplicada (2003).

49. Sistema Estadual de Análise de Dados Fundação. Índice de Vulnerabilidade juvenil (IVJ). São Paulo, Brazil: Fundação SEADE (2000).

50. Prefeitura Municipal de Belo Horizonte. Série histórica IQVU 1994-2000-2006: notas metodológicas. Orçamento e Informação: Belo Horizonte, Brazil: Secretaria Municipal de Planejamento (2008).

51. Gordon BG. Vulnerability in research: basic ethical concepts and general approach to review. $\operatorname{Toj}$ (2020). 20(1):34-38. doi:10.31486/toj.19.0079

52. Rufat $\mathrm{S}$, Tate E, Emrich CT, and Antolini F. How valid are social vulnerability models? Ann Am Assoc Geogr (2019). 109(4):1131-1153. doi:10.1080/ 24694452.2018.1535887

53. Parreira L, Marques da Costa E, and Ribeiro Filho V. Social vulnerability index for the state of minas gerais, Brazil: an analysis of geographical mesorregiões | Ĩndice de vulnerabilidade social para o estado de minas gerais, Brasil: uma análise das mesorregiões geográficas. Actas da Conferência Internacional Riscos. Segurança e Cidadania (International Conference Risk, Security and Citizenship Proceedings), 30. ICRSC/ Câmara Municipal de Setúbal (2017). p. 58-75. Available at: https://www. smpcb.pt/icrsc2017/downloads.htm

54. Abreu MA. Evolução urbana do Rio de Janeiro. Rio de Janeiro, Brazil: IPLANRIO-Jorge Zahar (1987).

55. Carvalho JM. Os bestializados: o Rio de Janeiro e a República que não foi. São Paulo, Brazil: Companhia das Letras (1987).

56. Ferreira A. Favelas no Rio de Janeiro: nascimento, expansão, remoção e, agora, exclusão através de muros. Revista Bibliográfica de Geografía y Ciencias Sociales (2009). 14(1):828. doi:10.1344/b3w.14.2009.25822

57. Instituto Brasileiro de Geografia e Estatística. Censo demográfico 2010: aglomerados subnormais - informações territoriais. Rio de Janeiro, Brazil: IBGE (2010). Available from: http://biblioteca.ibge.gov.br/visualizacao/ periodicos/552/cd_2010_agsn_if.pdf/ (Accessed December 10, 2015).
58. Alves HPF. Análise da vulnerabilidade socioambiental em Cubatão-SP por meio da integração de dados sociodemográficos e ambientais em escala intraurbana. Rev. bras. estud. (2013). 30(2). doi:10.1590/\$0102-30982013000200002

59. Barata MML, Bader DA, Derecznski C, Regoto P, and Rosenzweig C. Use of climate change projection for resilience planning in Rio de Janeiro, Brazil. Front Sustain Cities (2020). 2:28. doi:10.3389/frsc.2020.00028

60. Freitas CR, D'Avignon ALDA, and Castro AC. Urban social vulnerability and climate change in Rio de Janeiro city associated with population mobility. J Environ Pol Plann (2019). 21(6):797-810. doi:10.1080/1523908X.2019.1674135

61. Malczewski J. GIS-based multicriteria decision analysis: a survey of the literature. Int J Geographical Inf Sci (2006). 20(7):703-726. doi:10.1080/ 13658810600661508

62. Fundação Geo-Rio. Painel 2013: estamos preparados para as chuvas? Rio de Janeiro, Brazil: Fundação GEO-Rio (2013).

63. Miranda FM. Índice de susceptibilidade do meio físico a inundações como ferramenta para o planejamento urbano. [MS Dissertation]. Rio de Janeiro, Brazil: Universidade Federal do Rio de Janeiro (2016).

64. Instituto de Segurança Pública. Taxa de Letalidade violenta. Rio de Janeiro, Brazil: Instituto de Segurança Pública (2013).

65. Saaty TL. The analytic hierarchy process: planning, priority setting, resource allocation. New York, United States: McGraw-Hill International Book Co. (1980).

66. Gutterres ADS. O rumor E O terror $\mathrm{Na}$ construção de territórios de vulnerabilidade Na zona portuária do Rio de Janeiro. Mana (2016). 22(1): 179-209. doi:10.1590/0104-93132016v22n1p179

67. Malczewski J, and Ogryczak W. The multiple criteria location problem: 2. Preference-based techniques and interactive decision support. Environ Plan A (1996). 28(1):69-98. doi:10.1068/a280069

68. Sharifi MA, van den Toorn W, Rico A, and Emmanuel M. Application of GIS and multicriteria evaluation in locating sustainable boundary between the tunari National Park and Cochabamba City (Bolivia). J Multi-Criteria Decis Anal (2002). 11(1):151-164. doi:10.1002/mcda.323

69. Malczewski J. GIS-based land-use suitability analysis: a critical overview. Prog Plann (2004). 62(1):3-65. doi:10.1016/j.progress.2003.09.002

70. Joerin F, Thériault M, and Musy A. Using GIS and outranking multicriteria analysis for land-use suitability assessment. Int J Geogr Inf Sci (2001). 15(2): 153-174. doi:10.1080/13658810051030487

71. Sener S, Sener E, Nas B, and Karagüzel R. Combining AHP with GIS for landfill site selection: a case study in the Lake Beyșehir catchment area (Konya, Turkey). Waste Manag (2010). 30(1):2037-46. doi:10.1016/j.wasman.2010.05.024

72. Elsheikh RFA, Ouerghi S, and Elhag AR. Flood risk map based on GIS, and multi criteria techniques (case study Terengganu Malaysia). J Geogr Inf Syst (2015). 7(1):348-357. doi:10.4236/jgis.2015.74027

73. Wanyonyi JW, Imwati A, and Boitt M. GIS in analysis of potential sites for ecotourism - a case study of Kwale County. J Environ Sci Toxicol Food Tech (2016). 10(10):43-49. doi:10.9790/2402-1010014349

74. Myagmartseren P, Buyandelger M, and Brandt SA. Implications of a spatial multicriteria decision analysis for urban development in Ulaanbaatar, Mongolia. Math Prob Eng (2017). 2017:2819795. doi:10.1155/2017/2819795

75. Santos AP, Rocha SF, Abreu MVS, Calijuri ML, and Santos PM. O uso da análise multicritério no mapeamento da fragilidade social da área urbanizada do município de Viçosa - MG. Revista Brasileira de Cartografia (2012). 64(5):635-643.

76. Oliveira DBB, Rodrigues JP, Silva LF, and Oliveira PTS. Multi-criteria analysis in the strategic environmental assessment of the sugar and alcohol sector. Acta Scientiarum Technol (2012). 34(3):303-311. doi:10.4025/actascitechnol.v34i3.11525

77. Gomes EG, and Lins MPE. Integrating geographical information systems and multicriteria methods: a case study. Ann Oper Res (2002). 116(1):243-269. doi:10.1023/a:1021344700828

78. Jannuzzi PM, Miranda WL, and Silva DSG. Análise Multicritério e Tomada de Decisão em Políticas Públicas: aspectos Metodológicos, Aplicativo Operacional e Aplicações. Informática Pública (2009). 11(1):69-87.

79. Malta F, Marques da Costa E, and Magrini A. Análise da Vulnerabilidade socioambiental no Municipio do Rio de Janeiro. Revista Geo UERJ (2017). 30: 19-34. doi:10.12957/geouerj.2017.28311

80. Rodrigues AM. Desigualdades socioespaciais - a luta pelo direito à cidade. Cidades (2007). 4(6):73-88. doi:10.26895/geosaberes.v10i21.703

81. Rolnik R, and Klink J. Crescimento econômico e desenvolvimento urbano: por que nossas cidades continuam tão precárias? Novos Estudos - CEBRAP (2011) 89(1):89-109. doi:10.1590/s0101-33002011000100006 
82. Malta FS, Costa EMd, and Magrini A. Índice de vulnerabilidade socioambiental: uma proposta metodológica utilizando o caso do Rio de Janeiro, Brasil. Ciênc Saúde Coletiva (2017). 22(12):3933-3944. doi:10.1590/ 1413-812320172212.25032017

83. Malta F. Vulnerabilidade socioambiental: proposta metodológica e diagnóstico para o municipio do Rio de Janeiro. Rio de Janeiro, Brazil: Universidade Federal do Rio de Janeiro (2018).

84. Cohen SC, Cynamon SE, Kligerman DC, and Assumpção RF. Habitação saudável no Programa Saúde da Família (PSF): uma estratégia para as políticas públicas de saúde e ambiente. Ciênc Saúde Coletiva (2004). 9(3): 807-813. doi:10.1590/s1413-81232004000300031
85. Cohen SC, Bodstein R, Kligerman DC, and Marcondes WB. Habitação saudável e ambientes favoráveis à saúde como estratégia de promoção da saúde. Ciênc Saúde Coletiva (2007). 12(1):191-198. doi:10.1590/s1413-81232007000100022

Copyright (c) 2021 Malta and Marques da Costa. This is an open-access article distributed under the terms of the Creative Commons Attribution License (CC BY). The use, distribution or reproduction in other forums is permitted, provided the original author(s) and the copyright owner(s) are credited and that the original publication in this journal is cited, in accordance with accepted academic practice. No use, distribution or reproduction is permitted which does not comply with these terms. 